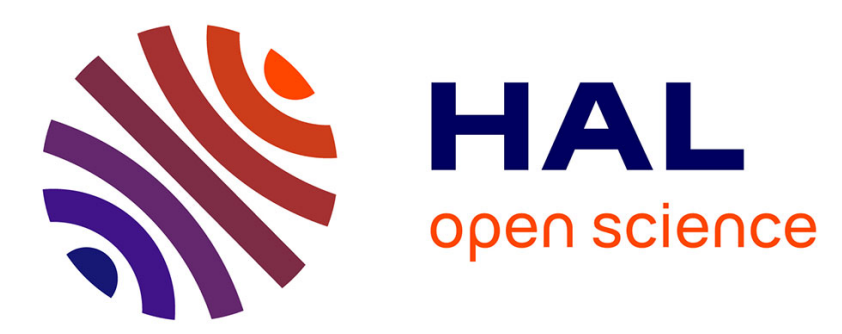

\title{
The involvement of rhamnolipids in microbial cell adhesion and biofilm development - an approach for control?
}

\author{
A. Nickzad, E. Déziel
}

\section{- To cite this version:}

A. Nickzad, E. Déziel. The involvement of rhamnolipids in microbial cell adhesion and biofilm development - an approach for control?. Letters in Applied Microbiology, 2013, 58 (5), pp.447-453. 10.1111/lam.12211. hal-01178793

\section{HAL Id: hal-01178793 \\ https://hal.science/hal-01178793}

Submitted on 21 Jul 2015

HAL is a multi-disciplinary open access archive for the deposit and dissemination of scientific research documents, whether they are published or not. The documents may come from teaching and research institutions in France or abroad, or from public or private research centers.
L'archive ouverte pluridisciplinaire HAL, est destinée au dépôt et à la diffusion de documents scientifiques de niveau recherche, publiés ou non, émanant des établissements d'enseignement et de recherche français ou étrangers, des laboratoires publics ou privés.

\section{(c)(1)}

Distributed under a Creative Commons Attribution| 4.0 International License 
UNDER THE MICROSCOPE

\title{
The involvement of rhamnolipids in microbial cell adhesion and biofilm development - an approach for control?
}

\author{
A. Nickzad and E. Déziel \\ INRS - Institut Armand-Frappier, Laval, QC, Canada
}

\author{
Keywords \\ biofilms, biosurfactants, Pseudomonas \\ aeruginosa.

\section{Correspondence} \\ Eric Déziel, INRS - Institut Armand-Frappier, \\ 531, Boul. des Prairies, Laval, QC, H7V 1B7, \\ Canada. \\ E-mail: eric.deziel@iaf.inrs.ca \\ 2013/1764: received 28 August 2013, revised \\ 19 December 2013 and accepted 20 \\ December 2013
}

doi:10.1111/lam.12211

\begin{abstract}
Biofilms are omnipresent in clinical and industrial settings and most of the times cause detrimental side effects. Finding efficient strategies to control surface-growing communities of micro-organisms remains a significant challenge. Rhamnolipids are extracellular secondary metabolites with surfaceactive properties mainly produced by Pseudomonas aeruginosa. There is growing evidence for the implication of this biosurfactant in different stages of biofilm development of this bacterium. Furthermore, rhamnolipids display a significant potential as anti-adhesive and disrupting agents against established biofilms formed by several bacterial and fungal species. Their low toxicity, biodegradability, efficiency and specificity, compared to synthetic surfactants typically used in biofilm control, might compensate for the economic hurdle still linked to their superior production costs and make them promising antifouling agents.
\end{abstract}

\section{Introduction}

Our idea of bacteria's lifestyle as loner planktonic organisms has dramatically changed; we rather consider them now as highly social organisms living in communities (Shapiro 1998). Living in a sessile community (typically a biofilm) is a trait which highly increases the survival fitness of bacteria facing unpredictable fluctuating and adverse conditions in their surroundings through augmenting their rate of adaptation and defence mechanisms (Davey and O'Toole 2000).

However, from our perspective, although often beneficial, biofilms are mostly regarded as harmful as they pose serious problems in industrial or clinical environment, either acting as biofouling agents or being the cause of the most resilient chronic medical device-associated infections in hospitalized patients (Hall-Stoodley et al. 2004).

This has led many studies to focus on identifying potential targets to control the detrimental biofilms both in industrial and clinical settings (Davies et al. 1998; Donlan 2009; Rendueles and Ghigo 2012).

In spite of recognizing potential targets, no efficient antibiofilm products have found way to the market yet, and this has been largely attributed to economic issues
(Romero and Kolter 2011). It is believed that finding an agent which targets a population-level trait and hence abolishes the chance of inducing resistance against its own action is highly promising and could weigh up against the existing economic hurdles (Boyle et al. 2013).

\section{Biosurfactants and their role in biofilms}

Biosurfactants are amphipathic molecules produced by a variety of bacteria, fungi and yeasts. Formed of both hydrophobic and hydrophilic moieties, these molecules act as surface-active agents in the microbial world and come with structural diversity and environmental compatibility (Desai and Banat 1997). Although several important functions for biosurfactants are known, questions remain concerning their natural roles and the mechanisms behind their production (Chrzanowski et al. 2012).

A number of studies have addressed the role of biosurfactant production in biofilm formation by different micro-organisms (Mireles et al. 2001; Walencka et al. 2008; Rivardo et al. 2009; Kanmani et al. 2011). For example, Kuiper et al. (2004) have shown that production of lipopeptide biosurfactants (putisolvins) by Pseudomonas 
putida is involved in development of its biofilm. Furthermore, putisolvins were not only able to inhibit the formation of biofilms by other Pseudomonas species, but also disrupt established ones. Similarly, the biosurfactant produced by Streptococcus thermophilus was effective in decreasing the initial adhesion of four bacterial and two yeast strains isolated from explanted voice prostheses to silicone rubber (Rodrigues et al. 2006a). Actually, the general potential of biosurfactants in altering cell surface properties of different micro-organisms and hence interfering with initial adhesion to solid surfaces and biofilm formation are increasingly investigated (Ron and Rosenberg 2001; Flemming and Wingender 2010; Rendueles and Ghigo 2012).

Probably the best studied model to investigate the involvement of a biosurfactant in adhesion and biofilm development is production of rhamnolipids by the opportunistic pathogen Pseudomonas aeruginosa. Rhamnolipids, which were first discovered in 1946 by Bergström et al., are surface-active glycolipids usually constituted of a dimer of 3-hydroxy fatty acids (typically from $C_{8}$ to $C_{12}$ length) linked via an O-glycosidic bond to a mono- or di-rhamnose moiety (Jarvis and Johnson 1949). Naturally produced rhamnolipids are always found as mixtures of different congeners (Déziel et al. 1999, 2000; AbdelMawgoud et al. 2010), and evidence shows that the individual molecules can exert different biological effects (Caiazza et al. 2005; Tremblay et al. 2007). Many functions have been attributed to these amphipathic exoproducts (see Abdel-Mawgoud et al. 2010 for a review); they were originally described as heat-stable haemolysins (Sierra 1960) and then intensely studied for their involvement in the assimilation of hydrocarbons (Hisatsuka et al. 1971) and as antimicrobials (Itoh et al. 1971).

In recent years, rhamnolipid production by Ps. aeruginosa has been increasingly shown to actually play an indispensable role in the establishment of the biofilm lifestyle, as they are involved in different stages of biofilm development, upon the earliest cell-to-surface interactions to maintenance and dispersion/disruption of the biofilm architecture (Davey et al. 2003). Rhamnolipids can function as virulence factor as they mediate the active dispersal of cells from biofilms, helping in the colonization of new sites and niches (Schooling et al. 2004). Moreover, they act as key protective agents of Ps. aeruginosa biofilm against phagocytes (Van Gennip et al. 2009). Besides, rhamnolipids display low toxicity, high biodegradability and effectiveness of their surface-active properties at wide range of temperatures, $\mathrm{pH}$ and salinity (Banat et al. 2000; AbdelMawgoud et al. 2011). The above evidence suggests that rhamnolipids might represent an attractive target to be exploited against their own producers and other biofilmforming microbes to control the colonization of surfaces.
In this review, we discuss the role of rhamnolipids in the development of biofilms and highlight their potential not only to disperse bacteria and fungi from biofilms, but also to prevent their formation.

\section{Rhamnolipids are actively involved in different stages of biofilm development}

The first published insights about the role of rhamnolipids in the structural regulation of biofilm development showed the ambivalent influence of rhamnolipids on impediment of biofilm development of Ps. aeruginosa depending on the spatiotemporal action of rhamnolipids; although the exogenous addition of rhamnolipids impeded initial bacterial adhesion, it had no effect on preformed biofilm (Davey et al. 2003). However, endogenous production of rhamnolipids in the biofilm could interfere with the final stages of biofilm formation (Davey et al. 2003). Hence, it could be concluded that the stability of the biofilm structure is dependent on the production of the appropriate amount of rhamnolipids at the right moment. Indeed, rhamnolipid producers have evolved intricate regulatory mechanisms to fulfil the timely expression of genes responsible for rhamnolipid biosynthesis. In support of this, Lequette and Greenberg (2005) showed stage-specific expression of the $r h l A B$ operon in Ps. aeruginosa biofilms. These genes encode the enzymes required for rhamnolipid biosynthesis (Ochsner et al. 1994a).

Moreover, regulation of rhamnolipid production in Ps. aeruginosa is controlled in a cell density-dependent manner through quorum sensing (Ochsner et al. 1994b; Ochsner and Reiser 1995) and exhibits partial cross-regulation by RpoS, which ensures precise timing of synthesis gene expression in biofilm, which is essential for the normal development of biofilm architecture (Medina et al. 2003).

\section{Adherence and microcolony formation}

For planktonic bacteria, initial adhesion to a surface can be regarded as the first and the most crucial step for further colonization (Palmer et al. 2007). Depending on the nature of the surface whether abiotic or biotic, multiple parameters, either nonspecific such as hydrophobicity, or specific such as the presence of particular molecules such as lectins, ligands or adhesins can be associated with the mechanism of adhesion (Dunne 2002). In this context, amphipathic molecules with interfacial activity such as rhamnolipids have the ability to alter cell-to-surface and cell-to-cell interactions and have the potential to diminish the ability of bacteria to adhere to the surfaces. While their overproduction inhibits biofilm development (Davey et al. 2003), depending on the concentration of rhamnolipids present, 
the result can be different. For instance, low concentration of rhamnolipids affects the cell surface properties through increasing cell hydrophobicity by causing a release of lipopolysaccharide from the cell surface, thereby increasing the affinity for initial adherence of cells to a surface (Zhang and Miller 1994; Al-Tahhan et al. 2000; Raya et al. 2010).

Once the bacteria attach to a surface, they begin clonal propagation and surface movement to form microcolonies (O’Toole and Kolter 1998). In agreement with the specific spatiotemporal role of rhamnolipids in biofilms, Pamp and Tolker-Nielsen (2007) demonstrated that rhamnolipids are necessary for the initial microcolony formation. In fact, it seems that increased hydrophobicity of cells induced by low concentration of rhamnolipids is sufficient enough to facilitate microcolony formation through enhancing aggregation of Ps. aeruginosa cells together (Herman et al. 1997; Pamp and Tolker-Nielsen 2007). While rhamnolipids seem indispensable for initial microcolony formation (Pamp and Tolker-Nielsen 2007), it is suggested that under certain conditions such as iron-limited biofilms, higher production of rhamnolipids induced by iron deficiency may contribute to increased twitching motility which, as a consequence, prevents initial microcolony formation (Patriquin et al. 2008). Again, it appears that the quantity of the produced rhamnolipids is a key to stability and balanced formation of microcolonies (Glick et al. 2010).

\section{Proliferation and formation of the differentiated biofilm}

In $P$ s. aeruginosa biofilms, at the onset of biofilm maturation, microcolonies act as platforms for formation of the stalk of the mushroom-like structures at certain foci (Klausen et al. 2003a,b). Then, through the emergence of a motile subpopulation, bacteria capable of migrating up the stalks form mushroom caps. For this kind of migration, bacteria require the presence of type IV pili and flagellum-mediated motility (Barken et al. 2008). Evidence that biosurfactant production is once again involved was presented as a rhlA mutant in mixed pilA/rhlA biofilms exhibited reduced cap formation, because of the lack of rhamnolipid production (Pamp and Tolker-Nielsen 2007). Then, once the mushroom-shaped structures are formed, another role of rhamnolipids is concerned with the maintenance of the highly hydrated structure of biofilms through prevention of colonization of the channels formed between these structures (Davey et al. 2003).

\section{Detachment and dispersion of planktonic cells}

Development of a biofilm typically culminates in the detachment and dispersal of cells (Kaplan 2010). This process has been mainly categorized into two different types of events according to the nature of the cues triggering the dispersion: passive, typically shear dependent, or active, which is a dynamic and highly regulated mechanism (McDougald et al. 2012). Seeding dispersion is an active mechanism, where detachment of cells occurs at late stages of biofilm formation and is actively mediated by rhamnolipids (Schooling et al. 2004; Boles et al. 2005; Wang et al. 2013). For instance, Boles et al. (2005) demonstrated that rhamnolipid-mediated detachment mechanism involves the formation of cavities within the centre of biofilm structures.

All together, evidence shows that rhamnolipids play a central role in biofilm development. As these surfaceactive molecules are well known to be essential, along with flagella, for the type of surface group behaviour called swarming motility (Déziel et al. 2003; Caiazza et al. 2005; Tremblay et al. 2007), it is hypothesized that swarming occurs inside the biofilm which leads to motility-associated dispersal (Wang et al. 2013).

Figure 1 summarizes the various functions attributed to rhamnolipids in bacterial adhesion to surfaces and biofilm development.

\section{From evidence to action}

As biofilm development involves similar steps in most bacterial species (O’Toole et al. 2000) and many bacteria require the production of surface-active molecules to express swarming motility (Kearns 2010; Partridge and Harshey 2013), modulating interaction between bacteria and surfaces via the use of biosurfactants such as rhamnolipids is naturally considered.

Indeed, Irie et al. (2005) demonstrated the ability of rhamnolipids to disperse preformed biofilms of Bordetella bronchiseptica. Moreover, the potent antibiofilm activity of rhamnolipids was evaluated against several microbial species associated with biofilm formation on voice prostheses and silicone rubber in the presence and absence of adsorbed rhamnolipids (Rodrigues et al. 2006b). The anti-adhesive activity of rhamnolipids at different concentrations was significant against all the strains and depended on the micro-organism tested, with a maximal initial reduction of adhesion rate (66\%) reported for strains of Streptococcus salivarius and Candida tropicalis (Rodrigues et al. 2006b). Furthermore, rhamnolipid conditioning of the silicon rubber caused a reduction of $48 \%$ in cell adherence of tested Staphylococcus epidermidis, Strep. salivarius, Staphylococcus aureus and C. tropicalis strains.

Further evidence on efficiency of rhamnolipids to inhibit initial adhesion of bacteria was recently reported by Sodagari et al. (2013). In this study, three Gram-negative species Ps. aeruginosa, Ps. putida and Escherichia coli and 


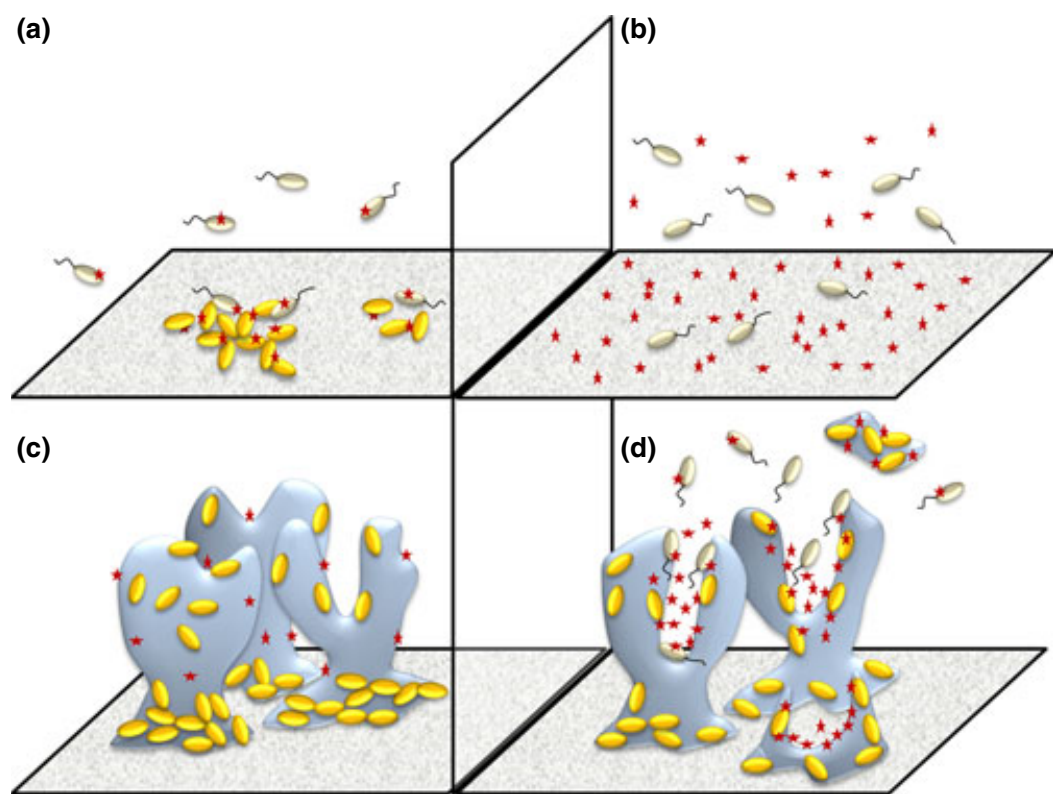

Figure 1 Representation of rhamnolipid implication in different stages of Pseudomonas aeruginosa biofilm development. (a) Low concentration of rhamnolipids increase affinity of cells for initial adherence to surfaces through increasing cell's surface hydrophobicity; (b) Presence of high concentrations of rhamnolipids in surrounding medium prevents attachment of cells and further microcolony formation; (c) At proliferation stage, rhamnolipids are actively involved in the maintenance of the complex-differentiated architecture of the biofilm; (d) At late stages of biofilm development, rhamnolipids promote seeding dispersal of motile cells. The red stars represent rhamnolipids.

two Gram-positive species Staph. epidermidis and Bacillus subtilis were assessed for their ability to establish biofilm on hydrophilic glass and hydrophobic octadecyltrichlorosilicone (OTS)-modified glass in the presence of two different concentrations of rhamnolipids. Rhamnolipids significantly reduced the attachment of all but Staph. epidermidis on both glass and OTS-modified glass. For Staph. epidermidis, rhamnolipids reduced the attachment on OTS-modified glass but not on glass. Several mechanisms might occur, and the authors investigated potential ones. For instance, rhamnolipids were found ineffective in modifying substratum surface properties and in facilitating the detachment of already attached cells, whereas rhamnolipids could inhibit the growth of B. subtilis, Staph. epidermidis and Ps. aeruginosa PAO1 but not the growth of E. coli, Ps. putida and Ps. aeruginosa E0340. Also, rhamnolipids were found effective in changing the cell surface hydrophobicity of the tested strains, although no clear effect was observed on B. subtilis. Despite the observed trends on cell detachment, the authors did not find any correlation with the potential mechanisms by which rhamnolipids influence cell detachment, and hence, the responsible mechanism(s) remained to be elucidated.

With regard to the biofouling problems, such as reduced heat transfer across heat exchanger surfaces, caused by bacterial biofilms in industrial settings exposed to the marine environment, Dusane et al. (2010) investigated the ability of rhamnolipids to inhibit adhesion and disrupt preformed Bacillus pumilus biofilms. The effectiveness of rhamnolipids to impair adhesion of B. pumilus cells to microtitre plates varied from 46 to $99 \%$ depend- ing on the concentrations of the rhamnolipids investigated $\left(0.05-100 \mathrm{mmol}^{-1}\right)$. The minimal inhibitory concentration (MIC) of rhamnolipids against planktonically growing $B$. pumilus was $1.6 \mathrm{mmol}^{-1}$, while a disruption of up to $93 \%$ of preformed B. pumilus biofilms was achieved at $100 \mathrm{mmol}^{-1}$, showing the effectiveness of rhamnolipids as promising compounds for inhibition/disruption of marine biofilms.

Apart from the efficacy of rhamnolipids against bacterial biofilms, a number of recent studies have also demonstrated the activity of rhamnolipids against fungal biofilms. Compared to conventional synthetic surfactants being used in medical settings such as cetyl trimethyl ammonium bromide (CTAB) and sodium dodecyl sulfate (SDS), Dusane et al. (2012) tested the potential of rhamnolipids to prevent biofilm formation and disrupt pre-established biofilms of the yeast Yarrowia lipolytica. In their study, precoating of microtitre plate wells with rhamnolipid effectively reduced Y. lipolytica biofilm formation by $50 \%$ as compared to CTAB, which inhibited by $29 \%$, and SDS which decreased biofilms by $<10 \%$ at their respective MIC values. Moreover, rhamnolipid displayed 55\% dispersion of Y. lipolytica biofilms (formed for 3 days in microtitre plate wells and treated for $1 \mathrm{~h}$ ), while 35\% disruption and 40\% disruption were observed with $\mathrm{CTAB}$ and SDS, respectively, at their respective MIC values.

Further evidence on effectiveness of rhamnolipids to disrupt fungal biofilms was recently shown by evaluating the potential of rhamnolipids to disrupt fungal biofilms of Candida albicans formed on polystyrene surfaces (Singh et al. 2013). Anti-adhesive activity of rhamnolipids 
on Candida cell adhesion was showed to be concentration dependent. About $50 \%$ of the cells remained adhered to 96-well plate after $2 \mathrm{~h}$ of treatment with $0.16 \mathrm{mg} \mathrm{ml}^{-1}$ of rhamnolipid; while up to $90 \%$ reduction in pre-established C. albicans biofilm on polystyrene surface was observed with rhamnolipid treatment at concentration of $5.0 \mathrm{mg} \mathrm{ml}^{-1}$ (Singh et al. 2013).

\section{Conclusion}

Taken together, the available literature supports the potential of rhamnolipids produced by Ps. aeruginosa as anti-adhesive and dispersing agents effective against established bacterial and fungal biofilms. Besides direct use in solution to disrupt already established biofilms in clinical and industrial settings, embedding of materials with rhamnolipids or surface coating might represent a promising approach to prevent the initial adhesion of bacteria and fungi. The environmental friendliness and specificity of biosurfactants might compensate for the economic hurdles still linked to their superior production costs as compared to the costs of synthetic surfactants.

\section{Acknowledgements}

Investigations on rhamnolipids in the ED laboratory are funded by the Natural Sciences and Engineering Research Council of Canada (NSERC) Discovery Grant No. 312478. ED holds a Canada Research Chair in Sociomicrobiology.

\section{Conflict of interest}

No conflict of interest declared.

\section{References}

Abdel-Mawgoud, A.M., Lépine, F. and Déziel, E. (2010) Rhamnolipids: diversity of structures, microbial origins and roles. Appl Microbiol Biotechnol 86, 1323-1336.

Abdel-Mawgoud, A., Hausmann, R., Lépine, F., Müller, M. and Déziel, E. (2011) Rhamnolipids: detection, analysis, biosynthesis, genetic regulation, and bioengineering of production. In Biosurfactants ed. Soberón-Chávez, G. pp. 13-55. Berlin Heidelberg: Springer.

Al-Tahhan, R.A., Sandrin, T.R., Bodour, A.A. and Maier, R.M. (2000) Rhamnolipid-induced removal of lipopolysaccharide from Pseudomonas aeruginosa: effect on cell surface properties and interaction with hydrophobic substrates. Appl Microbiol Biotechnol 66, 3262-3268.

Banat, I.M., Makkar, R.S. and Cameotra, S.S. (2000) Potential commercial applications of microbial surfactants. Appl Microbiol Biotechnol 53, 495-508.
Barken, K.B., Pamp, S.J., Yang, L., Gjermansen, M., Bertrand, J.J., Klausen, M., Givskov, M., Whitchurch, C.B. et al. (2008) Roles of type IV pili, flagellum-mediated motility and extracellular DNA in the formation of mature multicellular structures in Pseudomonas aeruginosa biofilms. Environ Microbiol 10, 2331-2343.

Bergström, S., Theorell, H. and Davide, H. (1946) On a metabolic product of Ps. pyocyania. Pyolipic acid active against M. tuberculosis. Arkiv Kemi Mineral Geol 8, 23A-1.

Boles, B.R., Thoendel, M. and Singh, P.K. (2005) Rhamnolipids mediate detachment of Pseudomonas aeruginosa from biofilms. Mol Microbiol 57, 1210-1223.

Boyle, K.E., Heilmann, S., van Ditmarsch, D. and Xavier, J.B. (2013) Exploiting social evolution in biofilms. Curr Opin Microbiol 16, 207-212.

Caiazza, N.C., Shanks, R.M. and O’Toole, G.A. (2005) Rhamnolipids modulate swarming motility patterns of Pseudomonas aeruginosa. J Bacteriol 187, 7351-7361.

Chrzanowski, Ł., Ławniczak, Ł. and Czaczyk, K. (2012) Why do microorganisms produce rhamnolipids? World J Microbiol Biotechnol 28, 401-419.

Davey, M.E. and O’Toole, G.A. (2000) Microbial biofilms: from ecology to molecular genetics. Microbiol Mol Biol Rev 64, 847-867.

Davey, M.E., Caiazza, N.C. and O’Toole, G.A. (2003) Rhamnolipid surfactant production affects biofilm architecture in Pseudomonas aeruginosa PAO1. J Bacteriol 185, 1027-1036.

Davies, D.G., Parsek, M.R., Pearson, J.P., Iglewski, B.H., Costerton, J.W. and Greenberg, E.P. (1998) The involvement of cell-to-cell signals in the development of a bacterial biofilm. Science 280, 295-298.

Desai, J.D. and Banat, I.M. (1997) Microbial production of surfactants and their commercial potential. Microbiol Mol Biol Rev 61, 47-64.

Déziel, E., Lépine, F., Dennie, D., Boismenu, D., Mamer, O.A. and Villemur, R. (1999) Liquid chromatography/mass spectrometry analysis of mixtures of rhamnolipids produced by Pseudomonas aeruginosa strain 57RP grown on mannitol or naphthalene. Biochim Biophys Acta 1440, 244-252.

Déziel, E., Lépine, F., Milot, S. and Villemur, R. (2000) Mass spectrometry monitoring of rhamnolipids from a growing culture of Pseudomonas aeruginosa strain 57RP. Biochim Biophys Acta 1485, 145-152.

Déziel, E., Lépine, F., Milot, S. and Villemur, R. (2003) rhlA is required for the production of a novel biosurfactant promoting swarming motility in Pseudomonas aeruginosa: 3-(3-hydroxyalkanoyloxy)alkanoic acids (HAAs), the precursors of rhamnolipids. Microbiol 149, 2005-2013.

Donlan, R.M. (2009) Preventing biofilms of clinically relevant organisms using bacteriophage. Trends Microbiol 17, 66-72.

Dunne, W.M. Jr (2002) Bacterial adhesion: seen any good biofilms lately? Clin Microbiol Rev 15, 155-166. 
Dusane, D.H., Nancharaiah, Y.V., Zinjarde, S.S. and Venugopalan, V.P. (2010) Rhamnolipid mediated disruption of marine Bacillus pumilus biofilms. Colloids Surf B Biointerfaces 81, 242-248.

Dusane, D.H., Dam, S., Nancharaiah, Y.V., Kumar, A.R., Venugopalan, V.P. and Zinjarde, S.S. (2012) Disruption of Yarrowia lipolytica biofilms by rhamnolipid biosurfactant. Aquat Biosyst 8, 17.

Flemming, H.C. and Wingender, J. (2010) The biofilm matrix. Nat Rev Microbiol 8, 623-633.

Glick, R., Gilmour, C., Tremblay, J., Satanower, S., Avidan, O., Deziel, E., Greenberg, E.P., Poole, K. et al. (2010) Increase in rhamnolipid synthesis under iron-limiting conditions influences surface motility and biofilm formation in Pseudomonas aeruginosa. J Bacteriol 192, 2973-2980.

Hall-Stoodley, L., Costerton, J.W. and Stoodley, P. (2004) Bacterial biofilms: from the natural environment to infectious diseases. Nat Rev Microbiol 2, 95-108.

Herman, D.C., Zhang, Y. and Miller, R.M. (1997) Rhamnolipid (biosurfactant) effects on cell aggregation and biodegradation of residual hexadecane under saturated flow conditions. Appl Environ Microbiol 63, 3622-3627.

Hisatsuka, K.-I., Nakahara, T., Sano, N. and Yamada, K. (1971) Formation of rhamnolipid by Pseudomonas aeruginosa and its function in hydrocarbon fermentation. Agr Biol Chem 35, 686-692.

Irie, Y., O’Toole, G.A. and Yuk, M.H. (2005) Pseudomonas aeruginosa rhamnolipids disperse Bordetella bronchiseptica biofilms. FEMS Microbiol Lett 250, 237-243.

Itoh, S., Honda, H., Tomita, F. and Suzuki, T. (1971) Rhamnolipids produced by Pseudomonas aeruginosa grown on n-paraffin (mixture of C 12, C 13 and C 14 fractions). J Antibiot (Tokyo) 24, 855-859.

Jarvis, F.G. and Johnson, M.J. (1949) A glycolipide produced by Pseudomonas aeruginosa. J Am Chem Soc 71, 4124-4126.

Kanmani, P., Satish kumar, R., Yuvaraj, N., Paari, K.A., Pattukumar, V. and Arul, V. (2011) Production and purification of a novel exopolysaccharide from lactic acid bacterium Streptococcus phocae PI80 and its functional characteristics activity in vitro. Bioresour Technol 102, 4827-4833.

Kaplan, J.B. (2010) Biofilm dispersal: mechanisms, clinical implications, and potential therapeutic uses. J Dent Res $\mathbf{8 9}$, 205-218.

Kearns, D.B. (2010) A field guide to bacterial swarming motility. Nat Rev Microbiol 8, 634-644.

Klausen, M., Aaes-Jorgensen, A., Molin, S. and Tolker-Nielsen, T. (2003a) Involvement of bacterial migration in the development of complex multicellular structures in Pseudomonas aeruginosa biofilms. Mol Microbiol 50, 61-68.

Klausen, M., Heydorn, A., Ragas, P., Lambertsen, L., AaesJorgensen, A., Molin, S. and Tolker-Nielsen, T. (2003b) Biofilm formation by Pseudomonas aeruginosa wild type, flagella and type IV pili mutants. Mol Microbiol 48, 1511-1524.
Kuiper, I., Lagendijk, E.L., Pickford, R., Derrick, J.P., Lamers, G.E.M., Thomas-Oates, J.E., Lugtenberg, B.J.J. and Bloemberg, G.V. (2004) Characterization of two Pseudomonas putida lipopeptide biosurfactants, putisolvin I and II, which inhibit biofilm formation and break down existing biofilms. Mol Microbiol 51, 97-113.

Lequette, Y. and Greenberg, E.P. (2005) Timing and localization of rhamnolipid synthesis gene expression in Pseudomonas aeruginosa biofilms. J Bacteriol 187, 37-44.

McDougald, D., Rice, S.A., Barraud, N., Steinberg, P.D. and Kjelleberg, S. (2012) Should we stay or should we go: mechanisms and ecological consequences for biofilm dispersal. Nat Rev Microbiol 10, 39-50.

Medina, G., Juarez, K. and Soberon-Chavez, G. (2003) The Pseudomonas aeruginosa rhlAB operon is not expressed during the logarithmic phase of growth even in the presence of its activator RhlR and the autoinducer Nbutyryl-homoserine lactone. J Bacteriol 185, 377-380.

Mireles, J.R. 2nd, Toguchi, A. and Harshey, R.M. (2001) Salmonella enterica serovar typhimurium swarming mutants with altered biofilm-forming abilities: surfactin inhibits biofilm formation. J Bacteriol 183, 5848-5854.

Ochsner, U.A. and Reiser, J. (1995) Autoinducer-mediated regulation of rhamnolipid biosurfactant synthesis in Pseudomonas aeruginosa. Proc Natl Acad Sci USA 92, 6424-6428.

Ochsner, U.A., Fiechter, A. and Reiser, J. (1994a) Isolation, characterization, and expression in Escherichia coli of the Pseudomonas aeruginosa rhlAB genes encoding a rhamnosyltransferase involved in rhamnolipid biosurfactant synthesis. J Biol Chem 269, 19787-19795.

Ochsner, U.A., Koch, A.K., Fiechter, A. and Reiser, J. (1994b) Isolation and characterization of a regulatory gene affecting rhamnolipid biosurfactant synthesis in Pseudomonas aeruginosa. J Bacteriol 176, 2044-2054.

O’Toole, G.A. and Kolter, R. (1998) Flagellar and twitching motility are necessary for Pseudomonas aeruginosa biofilm development. Mol Microbiol 30, 295-304.

O’Toole, G., Kaplan, H.B. and Kolter, R. (2000) Biofilm formation as microbial development. Annu Rev Microbiol 54, 49-79.

Palmer, J., Flint, S. and Brooks, J. (2007) Bacterial cell attachment, the beginning of a biofilm. J Ind Microbiol Biotechnol 34, 577-588.

Pamp, S.J. and Tolker-Nielsen, T. (2007) Multiple roles of biosurfactants in structural biofilm development by Pseudomonas aeruginosa. J Bacteriol 189, 2531-2539.

Partridge, J.D. and Harshey, R.M. (2013) Swarming: flexible roaming plans. J Bacteriol 195, 909-918.

Patriquin, G.M., Banin, E., Gilmour, C., Tuchman, R., Greenberg, E.P. and Poole, K. (2008) Influence of quorum sensing and iron on twitching motility and biofilm formation in Pseudomonas aeruginosa. J Bacteriol 190, 662-671.

Raya, A., Sodagari, M., Pinzon, N.M., He, X., Zhang Newby, B.M. and Ju, L.K. (2010) Effects of rhamnolipids and shear on 
initial attachment of Pseudomonas aeruginosa PAO1 in glass flow chambers. Environ Sci Pollut Res Int 17, 1529-1538.

Rendueles, O. and Ghigo, J.M. (2012) Multi-species biofilms: how to avoid unfriendly neighbors. FEMS Microbiol Rev 36, 972-989.

Rivardo, F., Turner, R.J., Allegrone, G., Ceri, H. and Martinotti, M.G. (2009) Anti-adhesion activity of two biosurfactants produced by Bacillus spp. prevents biofilm formation of human bacterial pathogens. Appl Microbiol Biotechnol 83, 541-553.

Rodrigues, L., van der Mei, H., Banat, I.M., Teixeira, J. and Oliveira, R. (2006a) Inhibition of microbial adhesion to silicone rubber treated with biosurfactant from Streptococcus thermophilus A. FEMS Immunol Med Microbiol 46, 107-112.

Rodrigues, L.R., Banat, I.M., van der Mei, H.C., Teixeira, J.A. and Oliveira, R. (2006b) Interference in adhesion of bacteria and yeasts isolated from explanted voice prostheses to silicone rubber by rhamnolipid biosurfactants. J Appl Microbiol 100, 470-480.

Romero, D. and Kolter, R. (2011) Will biofilm disassembly agents make it to market? Trends Microbiol 19, 304-306.

Ron, E.Z. and Rosenberg, E. (2001) Natural roles of biosurfactants. Environ Microbiol 3, 229-236.

Schooling, S.R., Charaf, U.K., Allison, D.G. and Gilbert, P. (2004) A role for rhamnolipid in biofilm dispersion. Biofilms 1, 91-99.

Shapiro, J.A. (1998) Thinking about bacterial populations as multicellular organisms. Annu Rev Microbiol 52, 81-104.

Sierra, G. (1960) Hemolytic effect of a glycolipid produced by Pseudomonas aeruginosa. Antonie Van Leeuwenhoek 26, 189-192.
Singh, N., Pemmaraju, S.C., Pruthi, P.A., Cameotra, S.S. and Pruthi, V. (2013) Candida biofilm disrupting ability of dirhamnolipid (RL-2) produced from Pseudomonas aeruginosa DSVP20. Appl Biochem Biotechnol 169, 2374-2391.

Sodagari, M., Wang, H., Newby, B.M. and Ju, L.K. (2013) Effect of rhamnolipids on initial attachment of bacteria on glass and octadecyltrichlorosilane-modified glass. Colloids Surf B Biointerfaces 103, 121-128.

Tremblay, J., Richardson, A.P., Lepine, F. and Deziel, E. (2007) Self-produced extracellular stimuli modulate the Pseudomonas aeruginosa swarming motility behaviour. Environ Microbiol 9, 2622-2630.

Van Gennip, M., Christensen, L.D., Alhede, M., Phipps, R., Jensen, P.O., Christophersen, L., Pamp, S.J., Moser, C. et al. (2009) Inactivation of the rhlA gene in Pseudomonas aeruginosa prevents rhamnolipid production, disabling the protection against polymorphonuclear leukocytes. APMIS 117, 537-546.

Walencka, E., Rozalska, S., Sadowska, B. and Rozalska, B. (2008) The influence of Lactobacillus acidophilus-derived surfactants on staphylococcal adhesion and biofilm formation. Folia Microbiol (Praha) 53, 61-66.

Wang, J., Yu, B., Tian, D. and Ni, M. (2013) Rhamnolipid but not motility is associated with the initiation of biofilm seeding dispersal of Pseudomonas aeruginosa strain PA17. J Biosci 38, 149-156.

Zhang, Y. and Miller, R.M. (1994) Effect of a Pseudomonas rhamnolipid biosurfactant on cell hydrophobicity and biodegradation of octadecane. Appl Environ Microbiol 60, 2101-2106. 